\title{
Dispositivo fotobiomodulador para prevenção e tratamento de hiperqueratose de teto em vacas leiteiras ${ }^{1}$
}

\author{
Pedro G. Lage ${ }^{2}$, Angélica R. Araújo ${ }^{3}$, Alexandre G. Teixeira ${ }^{4}$, Marcos Pinotti ${ }^{5}$ \\ e Rafael R. Faleiros ${ }^{2 *}$
}

\begin{abstract}
Lage P.G., Araújo A.R., Teixeira A.G., Pinotti M. \& Faleiros R.R. 2014. [Photobiomodulation device for prevention and treatment of teat hyperkeratosis in dairy cows.] Dispositivo fotobiomodulador para prevenção e tratamento de hiperqueratose de teto em vacas leiteiras. Pesquisa Veterinária Brasileira 34(6):515-522. Departamento de Clínica e Cirurgia Veterinárias, Escola de Veterinária da Universidade Federal de Minas Gerais, Av Antonio Carlos 6627, Belo Horizonte, MG 31270-901, Brazil. E-mail: faleirosufmg@gmail.com

Mastitis consistis one of the main problems of milk production, mainly due to the production losses and the rising cost of milk. In case of severe hyperkeratosis, the teat canal can become an easier barrier for the bacteria to penetrate. The objeSctive of this study was to assess a phototherapy device construct with LED light for prevention and treatment of teat hyperkeratosis in a dairy cattle herd with high prevalence $(35.3 \%$ of severe cases). 60 primiparous cows were used in the preventive experiment and 30 cows with hyperkeratosis were used in the therapeutic experiment. In both experiments, half of the cows started to be treated in early lactation using the phototherapy device three times per week for 6 weeks. The other cows were the controls. Hyperkeratosis was assessed by scoring and by morphometric analyses of teat images that were taken at baseline and then weekly for 6 consecutive weeks. In the preventive experiment, more images were taken later, between 6 and 7 months of the first lactation. Somatic cell counts (SCC) were performed monthly. In the preventive experiment, the outer diameter of the teat lesions remained constant in the treated group, whereas cows of the control group showed a significant increase at the end of lactation. In the therapeutic groups, no statistical differences for teat hyperkeratosis variables were seen between groups. However, the incidence of subclinical mastitis (SCC $>250$ cells $/ \mathrm{mL}$ ) during lactation was lower in the treated group $(\mathrm{P}<0.05)$. In conclusion the phototherapy protocol did not prevent the development in primiparous or ameliorate previous hyperkeratosis lesions in cows. However, the prototype was considered useful as an adjunct in preventing the increase in the size of teat hyperkeratosis lesions and also as a way to reduce subclinical mastitis incidence in affected dairy cows.
\end{abstract}

INDEX TERMS: Teat hyperkeratosis, mastitis, phototherapy, LED, dairy cattle.

\footnotetext{
${ }^{1}$ Recebido em 6 de março de 2014.

Aceito para publicação em 12 de maio de 2014.

${ }^{2}$ Departamento de Clínica e Cirurgia Veterinárias, Escola de Veterinária, Universidade Federal de Minas Gerais (UFMG), Av. Antonio Carlos 6627, Belo Horizonte, MG 31270-901, Brasil. *Autor para correspondência: faleirosufmg@gmail.com

${ }^{3}$ Rua Castelo de Windsor 475/302, Bairro Castelo, Belo Horizonte, MG 31330-180.

${ }^{4}$ Bios Eletrônica e Informática, Rodovia LMG-800 Km 1 no. 128a, Distrito Industrial Genesco Aparecido Oliveira, Lagoa Santa, MG 33400-000, Brasil.

${ }^{5}$ Bioengineering Laboratory (Labbio), Departamento de Engenharia Mecânica, Escola de Engenharia, UFMG, Av. Antonio Carlos 6627, Belo Horizonte, MG 31270-901.
}

RESUMO.- As mastites estão entre as principais causas de prejuízo para produtores de leite. Em casos graves de hiperqueratose, o canal do teto pode se tornar uma barreira mais fácil para que as bactérias penetrem na glândula mamária. Os objetivos deste estudo foram avaliar um dispositivo fotobiomodulador de LED para tratamento e prevenção de hiperqueratose de teto e prevenção da mastite subclínica em um rebanho de leite com alta prevalência de hiperqueratose $(35,3 \%$ de casos graves). Foram utilizadas 60 primíparas para o experimento de prevenção e 30 vacas com hiperqueratose para o experimento terapêutico. Em ambos os experimentos, metade dos animais foram 
tratados com o dispositivo fotobiomodulador três vezes por semana, durante 6 semanas. Os outros animais foram os controles. Imagens fotográficas digitalizadas foram realizadas na avaliação inicial e, semanalmente, por 6 semanas consecutivas. Nas primíparas, novas avaliações foram realizadas entre 6 e 7 meses de lactação. Para avaliação da mastite subclínica, contagem de células somáticas (CCS) foram feitas mensalmente. No experimento preventivo, o diâmetro externo das lesões permaneceu constante nos tetos do grupo tratado, enquanto houve aumento no grupo controle. No experimento terapêutico não foram observadas diferenças estatísticas entre as variáveis de hiperqueratose. Contudo, o grupo tratado apresentou menor incidência de mastites subclínicas (CCS $<250$ células $/ \mathrm{mL}$ ) por lactação do que o grupo controle $(\mathrm{P}<0,05)$. Em conclusão, o tratamento não foi efetivo em prevenir o desenvolvimento ou reduzir lesões instaladas de hiperqueratose de teto. Contudo, o uso protótipo se mostrou útil e promissor como adjuvante na prevenção do aumento de tamanho das lesões de hiperqueratose de teto em primíparas e como forma de reduzir incidência de mastite subclínicas em vacas leiteiras já acometidas.

TERMOS DE INDEXAÇÃO: Hiperqueratose de teto, mastite, fototerapia, LED, gado de leite.

\section{INTRODUÇÃO}

O Brasil produziu 29.112.024 mil litros de leite em 2009, sendo o estado de Minas Gerais o maior produtor do país com 7.931.115 mil litros de leite. Este número corresponde a $27,2 \%$ da produção nacional (IBGE 2009). De acordo com a projeção, a produção de leite deve crescer 1,95\% ao ano e ultrapassar, em 2020, os 37 bilhões de litros (Brasil 2010). A produção de leite, como acontece em outros segmentos de produção da atual sociedade, é uma atividade cada vez mais competitiva. Portanto, é importante quantificar e qualificar os fatores que podem influenciá-la, buscando ganhos efetivos na quantidade e qualidade do leite produzido, na tentativa de suprir a demanda nacional (Coldebella et al. 2004).

As mastites constituem um dos principais problemas da produção leiteira, devido principalmente às perdas de produção e ao aumento dos custos do leite (Sandholm et al. 1995). A ocorrência da mastite, inflamação da glândula mamaria, está relacionada ao desequilíbrio entre a resistência da vaca, a patogenicidade do agente e o ambiente. A resistência do animal tem impacto direto sobre o desenvolvimento da mastite, abrangendo além da imunidade, características anatômicas dos tetos e úbere, estágio de lactação, número de partos e adequação nutricional (Santos \& Fonseca 2007).

A hiperqueratose é uma reação do canal do teto a alguns estímulos que provocam o aumento da sua espessura e rugosidade, principalmente pelo acúmulo de grandes quantidades de queratina. A ação mecânica exercida durante a ordenha é o principal fator desencadeador desta alteração (Capuco et al. 1998). Uma pequena quantidade de hiperqueratose não parece aumentar o risco de uma infecção intra-mamária na vaca em lactação, podendo ser considerada como um benefício fisiológico na resposta do teto à ordenha. Um grau maior de hiperqueratose está associado com o aumento da probabilidade de novas infecções intramamárias. A avaliação da hiperqueratose em rebanhos comerciais pode ajudar a identificar ou a resolver problemas relacionados com o manejo da ordenha, com o meio ambiente ou com a ordenhadeira (Nein et al. 2003).

Estudos têm demonstrado que a radiação tecidual com fontes de luz com baixa intensidade, como o diodo emissor de luz (LED) de baixa intensidade, na faixa do vermelho ao infravermelho próximo, pode ser uma estratégia efetiva para modular a dor e favorecer o processo de cicatrização tecidual (Lagan et al. 2000, Lucas et al. 2003, Takezaki et al. 2006). Os benefícios do LED e do laser de baixa intensidade têm sido observados em condições tais como osteoartrite, radiculopatias, tendinites e, principalmente, no tratamento de feridas cutâneas em animais (Kana et al. 1981, Soares et al. 1989, Matera et al. 2003) e em humanos (Corrêa et al. 2003, Siqueira et al. 2004).

O objetivo deste estudo foi avaliar um dispositivo fotobiomodulador, que se utiliza de LEDs com comprimento de onda na faixa espectral do vermelho ao infravermelho próximo, para tratamento e prevenção de hiperqueratose de teto em rebanho de leite. Além disso, verificou-se o efeito uso do dispositivo na incidência de mastite subclínica por meio do monitoramento da contagem de células somáticas em animais submetidos ou não ao tratamento.

\section{MATERIAL E MÉTODOS}

Este estudo foi aprovado pelo Comitê de Ética em Experimentação Animal (CETEA) da Universidade Federal de Minas Gerais, protocolo 196/07. O experimento foi realizado no período outubro a novembro de 2010 com um retorno em maio de 2011, em uma Fazenda a $80 \mathrm{~km}$ de Belo Horizonte/MG. A propriedade produzia em média 35 mil litros por dia, com cerca de 1200 vacas em lactação. A partir dessa população, foi possível escolher com considerável critério os animais para entrar no experimento.

0 equipamento de ordenha era da marca DeLaval, em linha baixa, duplo 24/48, com extratores automáticos. A empresa fazia revisão programada regularmente, a cada quatro meses, em todo o equipamento, conforme descrito no Quadro 1 . Todos os funcionários passaram por treinamento na própria fazenda antes de começarem a trabalhar com os equipamentos. Todos os animais ficavam estabulados em free stall, com controle da umidade e temperatura feita por ventiladores e aspersores. Os locais de ordenha tinham o piso constantemente limpo e lavados, para evitar acúmulo de matéria orgânica. A remoção do conjunto de ordenha era realizada por extração automática, a fim de evitar a sobre ordenha. Eram realizadas três ordenhas diárias, com produção média de 29 litros de leite/vaca/dia ou 9210 litros/vaca/ano.

Quadro1. Calendário das revisões do equipamento de ordenha

\begin{tabular}{lc}
\hline \multicolumn{1}{c}{ Tarefas } & Frequência \\
\hline $\begin{array}{l}\text { Verificar o nível do vácuo } \\
\text { Verificar o nível de Óleo e } \\
\text { tensão de corra da bomba }\end{array}$ & Diário \\
Substituir os filtro dos & Semanal \\
pulsadores e regular o vácuo & mensal \\
Substituir os insulfladores & \\
Troca das mangueiras e outras & 2500 ordenhas, 40 dias \\
partes de borracha do sistema & Trimestral \\
Revisão completa em todo equipamento & \\
\end{tabular}


Inicialmente, com o intuito de se entender a dinâmica e a epidemiologia da hiperqueratose no rebanho, realizou-se um estudo observacional visando entender a prevalência dessa lesão em diferentes categorias de vacas, considerando-se os diferentes meses de lactação. Para tanto, dois pesquisadores acompanharam a ordenha de todas as vacas em um único dia, classificando a presença de hiperqueratose nos tetos em graus de um a quatro. Utilizou-se a escala proposta por Mein et al. (2001) sendo grau 1 (normal); a ponta do teto se apresenta lisa e possui um orifício pequeno; grau 2 , a ponta do teto é lisa ou ligeiramente áspera e apresenta uma ligeira calosidade em forma de anel, projetando-se a partir do orifício; grau 3, a calosidade está em relevo destacado, com superfície áspera e com camada de queratina de 1-3 mm acima do orifício; e grau 4, a calosidade apresenta superfície muito áspera com camada de queratina superior a $4 \mathrm{~mm}$, muitas vezes quebradiça. As avaliações seguiram as recomendações descritas no Latest Thoughts on Methods for Assessing Teat Condition elaboradas pelo Teat Club International (Neijenhuis et al. 2001, Reinemann s.d.). Posteriormente, as vacas foram classificadas quanto ao número de partos e o mês de lactação, de forma a verificar o efeito do tempo de exposição à ação da ordenhadeira no aparecimento e progressão da hiperqueratose de teto ao longo da primeira, da segunda e da terceira lactação.

Experimento preventivo - Avaliação do possível efeito preventivo da fototerapia sobre o desenvolvimento da hiperqueratose de teto. Com base nos resultados do estudo observacional, foram selecionadas 60 primíparas em início de lactação (entre 8 e 78 dias), sem histórico ou sinais clínicos de qualquer tipo de afecção mamária, com todos os quartos funcionais e negativos para a presença de mastite clínica pelo teste da caneca de fundo preto. Tais primíparas foram dividas aleatoriamente em dois grupos de 30 animais, um controle e um tratado.

As primíparas do grupo tratado tiveram o teto cranial esquerdo submetido à fototerapia, com a utilização do protótipo de fotobiomodulação registrado no INPI pelo registro PI0905068 (Fig. 1). A ação do protótipo se baseia na emissão de luz do tipo LED, por emissores posicionados em torno do óstio do teto. 0 teto cranial direito do grupo tratado, apesar de não receber tratamento, também foi avaliado no sentido de verificar um possível efeito da fototerapia contralateral. Para tanto, em um período máximo de duas horas após a ordenha, os animais do grupo tratado foram contidos em tronco para que o protótipo fosse aplicado por um período de 2 minutos. Este procedimento foi repetido três vezes por semana por um período de seis semanas (18 aplicações). Antes de cada aplicação, como os tetos chegavam com a solução an- tisséptica, essa solução era retirada com o papel toalha e após a aplicação era novamente colocada.

Durante todo o período experimental, ambos os grupos permaneceram no mesmo lote de vacas, recebendo o mesmo tipo de alimentação e manejo e sendo ordenhados em conjunto nas mesmas instalações e com o mesmo equipamento. Como medida de prevenção de mastite, antes da ordenha, os tetos eram limpos com solução de cloro $1 \%$, feito o teste da caneca de fundo preto, imersos na mesma solução de cloro $1 \%$, deixado agir por 30 segundos era retirado com papel toalha e imediatamente era colocado o conjunto de ordenha. Imediatamente após a ordenha, os tetos de todos os animais foram imersos em solução iodo glicerinado, $1 \%$ de iodo ativo. Como medida de controle, a Fazenda realizava mensalmente a contagem de células somáticas de todas as vacas em lactação.

Antes do início, durante o experimento, semanalmente por seis semanas consecutivas, e seis meses após o final, a extremidade distal dos tetos craniais das vacas de ambos os grupos foram fotografados pelo mesmo pelo mesmo pesquisador, a fim de classificar a hiperqueratose pelo sistema de escores conforme descrito e realizar a morfometria da lesão.

As fotografias foram obtidas de forma padronizada por meio de uma câmera EOS Rebel XS (Canon, EUA), 10.1 megapixels, com lente de 18 x $55 \mathrm{~mm}$, a uma distância constante de $30 \mathrm{~cm}$ (mantida sempre na lente de $55 \mathrm{~mm}$ com o estabilizador e com o foco no modo automático). Para se manter a distância constante até a lesão, uma régua metálica dotada de um gabarito de $1 \mathrm{~cm}^{2}$ (Figura 2) foi adaptada à base da câmera. Em cada tempo, foram realizadas duas imagens de boa qualidade por teto avaliado. As imagens capturadas foram transferidas para um computador pessoal para serem posteriormente analisados por meio do programa computacional MATLAB 7.0.1, para obtenção das áreas externas e internas da lesão (Fig.2). Este procedimento foi realizado por três pessoas independentes e cegas quanto à identificação do grupo ou tempo da imagem analisada.

Experimento terapêutico - Avaliação do possível efeito terapêutico da fototerapia sobre a cicatrização da hiperqueratose de teto. Para esse experimento foram selecionadas 30 vacas de segunda lactação, que já apresentavam lesão de hiperqueratose prévia. Com base nos resultados do estudo observacional, as todas as vacas iniciaram no experimento entre 156 e 256 dias de lactação, quando a lesão de hiperqueratose já estava estabilizada. De forma semelhante ao experimento II as vacas possuíam todos os quartos funcionais, sem sinais clínicos de qualquer tipo de afecção mamária e negativos para a presença de mastite clínica

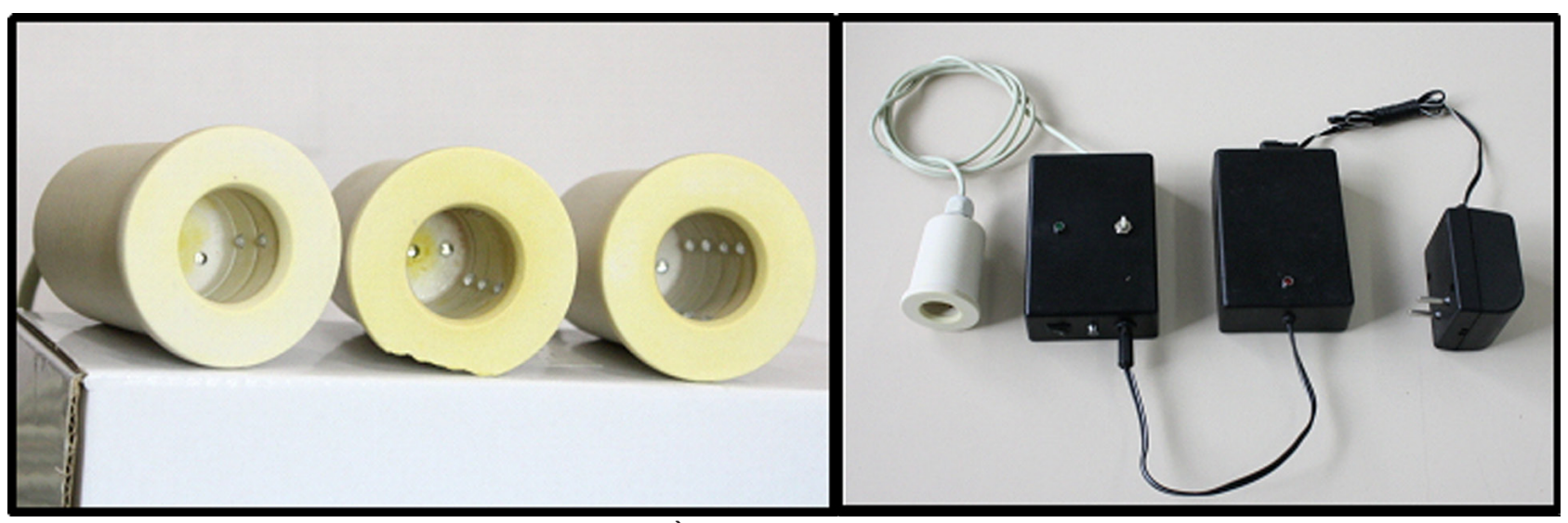

Fig.1. Protótipo de fotobiomodulação (INPI PI0905068). À esquerda, dispositivos em forma de teteira, de três diferentes tamanhos, com unidades de LED dispostas em seu interior. À direita, o conjunto montado com o dispositivo em forma de teteira, a bateria e o carregador. 

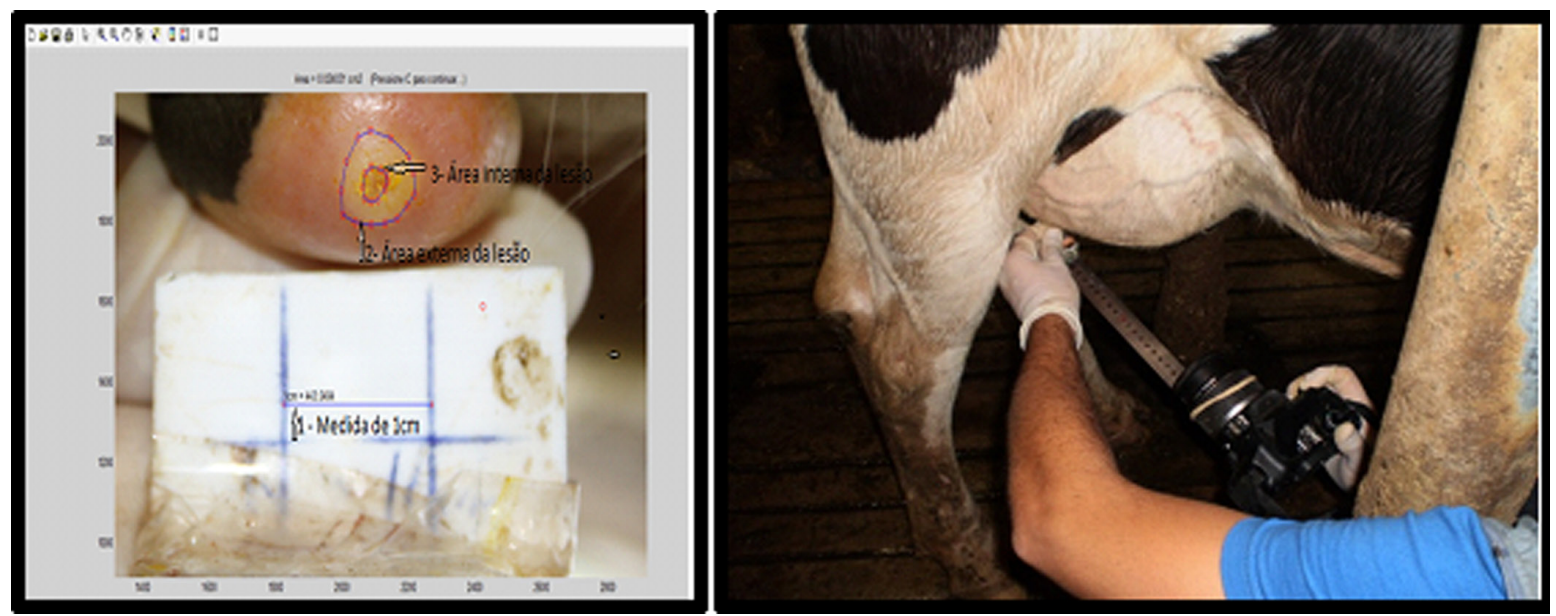

Fig.2. Técnica de obtenção de imagens para mensuração da área de hiperqueratose. À direita observa-se o momento da obtenção da imagem com câmera fixada à régua metálica, que serviu para padronização da distância. À esquerda, observa-se imagem capturada mostrando a mensuração das áreas interna e externa da hiperqueratose, com auxílio do programa MATLAB 7.0.1. Para calibração, utilizou-se uma distância conhecida entre linhas azuis de $1 \mathrm{~cm}$, que foi gravada em uma aparato de plástico fixado à extremidade livre a régua.

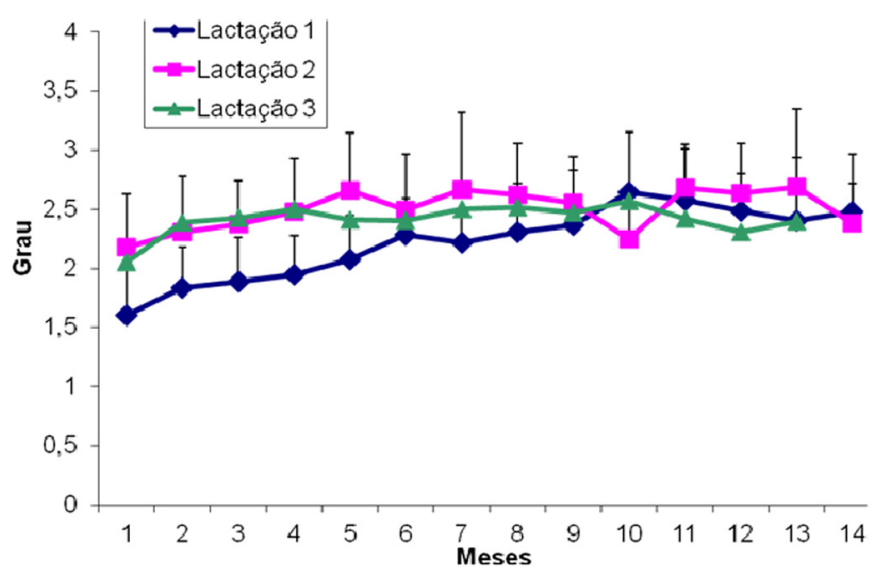

Fig.3. Médias e desvios padrões dos graus de hiperqueratose segundo o número de partos e o tempo de lactação em vacas da raça HPB.

pelo teste da caneca. Estas vacas foram dividas aleatoriamente em dois grupos de 15 animais, um controle e um tratado.

Durante o experimento foram retirados dois animais, sendo um animal tratado e outro controle, eles ficaram mais de uma semana em outra ordenha para tratamento de mastites recorrentes. 0 tratamento e as avaliações foram realizados da mesma forma que nas primíparas de prevenção, com exceção do último tempo de avaliação de seis meses após o final, não realizado neste experimento.

Análise estatística. Os dados do estudo observacional foram tabulados, calculando-se médias e desvios padrões de acordo com os diferentes meses de lactação, considerando-se separadamente categorias de vacas de primeira, segunda e terceira lactações. Esses dados foram representados em forma de gráficos de linhas para visualizar a evolução das lesões nas diferentes categorias.

Os dados dos experimentos preventivo e terapêutico foram tabulados e apresentados em forma de médias e erros padrões. No caso dos escores para hiperqueratose, verificou-se o efeito do tratamento em cada tempo por meio do teste de Kruskal Wallis, seguido pelo teste de Dunn para comparar as médias do teto tratado (esquerdo) e controle (direito) do grupo controle jun- tamente com os tetos esquerdo (controle 1) e direito (controle 2) do grupo controle. Para comparação dos diferentes tempos em cada teto, usou-se do teste de Friedman seguido pelo teste de Dunn.

Para os dados paramétricos (medidas interna e externa e CCS) utilizou-se ANOVA inteiramente casualizado para o efeito do tratamento entre tempos e ANOVA em blocos ao acaso para comparação de tempos em cada teto. Em ambos os casos, comparou-se médias pelo teste de Tukey. No caso das medidas internas e externas o valor de cada teto foi representado pela média aritmética dos três avaliadores.

Para a comparação da incidência de mastite subclínica (CCS $>250$ células/mL) entre grupos durante o período experimental, usou-se o teste exato de Fisher nos dois experimentos. Quando o teste de Fisher foi significativo, calculou-se a razão de chances (odds ratio) e seu intervalo de confiança a 95\%. Para todos os testes estatísticos considerou-se um nível de significância de $\mathrm{P} \leq 0,05$.

\section{RESULTADOS}

Por meio do estudo observacional, 3964 tetos de 991 vacas foram examinados, verificando-se uma incidência geral de hiperqueratose nessa população de $95,6 \%$ dos tetos afetados, sendo $60,3 \%$ com grau $2,32,1 \%$ no grau 3 e $32,2 \%$ com grau 4. As médias e os desvios padrões dos graus de hiperqueratose nos diferentes meses de lactação nas categorias de vacas de primeira, segunda e terceira lactação estão representados na Figura 3.

Quanto ao experimento preventivo, realizado nas primíparas, os valores médios para áreas internas e externas e graus de hiperqueratose dos tetos tratado (esquerdo) e contralateral (direito) do grupo tratado e os dois tetos do grupo controle (controles 1 e 2) estão representados, respectivamente, nas Fig. 4, 5 e 6. Durante a lactação dessas primíparas, as incidências de mastite subclínica, caracterizada pela ocorrência de CCS acima de 250 células, foram de $19,5 \%$ no grupo controle e $19 \%$ no grupo tratado, não havendo diferença estatística entre elas.

Sobre o experimento terapêutico, realizado com as 
Primiparas - Área Externa
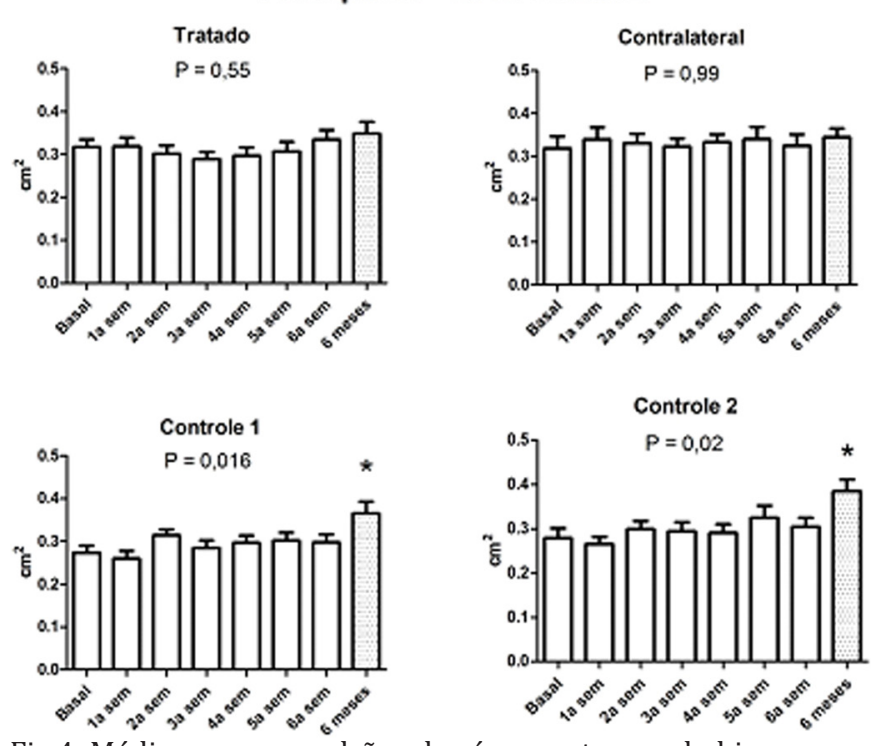

Fig.4. Médias e erros padrões das áreas externas de hiperqueratose de tetos em primíparas submetidas ou não à terapia fotobiomoduladora.

\section{Primíparas - Área Interna}
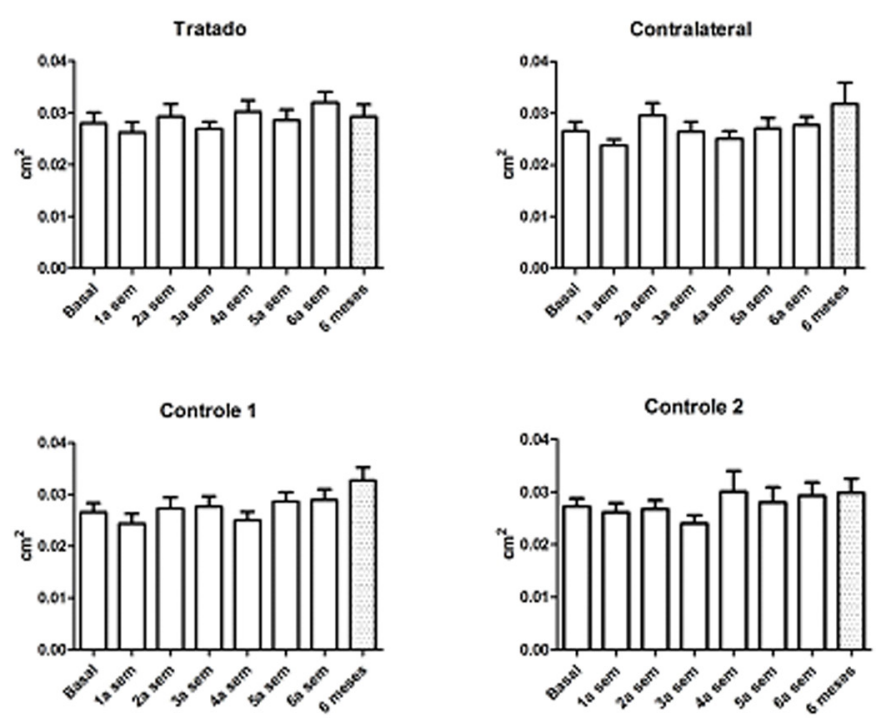

Fig.5. Médias e erros padrões das áreas internas de hiperqueratose de tetos em primíparas submetidas ou não à terapia fotobiomoduladora.

vacas de segunda lactação, os valores médios para áreas internas e externas e graus de hiperqueratose dos tetos tratado (esquerdo) e contralateral (direito) do grupo tratado e os dois tetos do grupo controle (controles 1 e 2) estão representados respectivamente nas Figuras 7, 8 e 9. Durante a lactação dessas multíparas, as incidências de mastite subclínica, caracterizada pela ocorrência de CCS acima de 250 células, foram de $46 \%$ no grupo controle e $28 \%$ no grupo tratado, havendo diferença estatística $(\mathrm{P}=0,02)$ entre elas. 0 teste de odds ratio demonstrou que vacas controle tiveram 2,15 (IC 95\%: 1,11 a 4,15 ) vezes mais chance de apresentar mastite subclínica que as vacas tratadas.

\section{Primíparas - Escore}
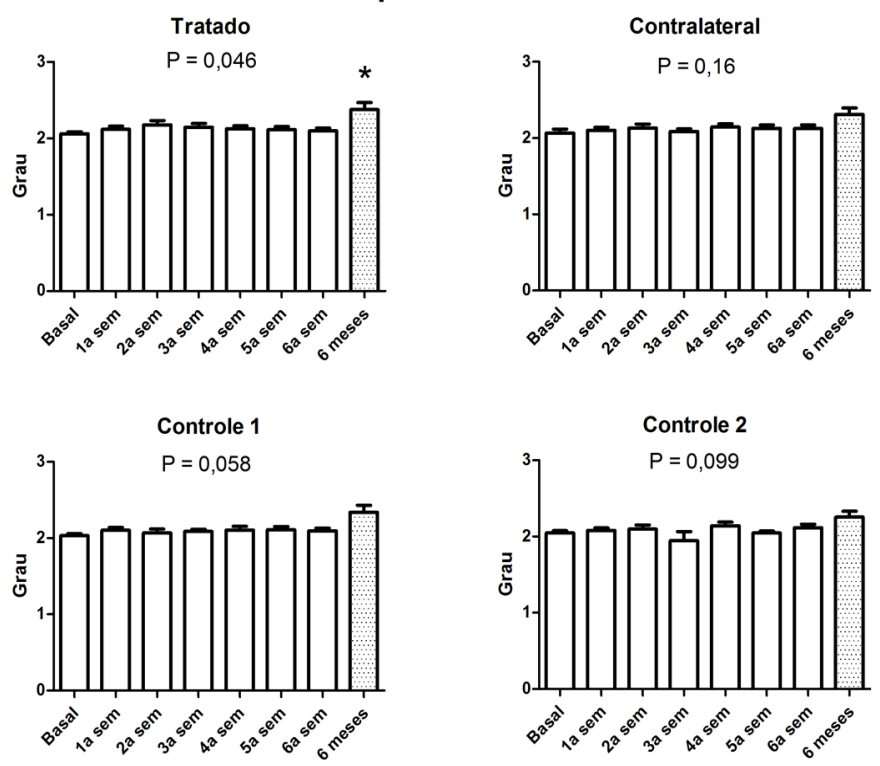

Fig.6. Médias e erros padrões dos graus de hiperqueratose de tetos em primíparas submetidas ou não à terapia fotobiomoduladora.

\section{Vacas - Área Externa}
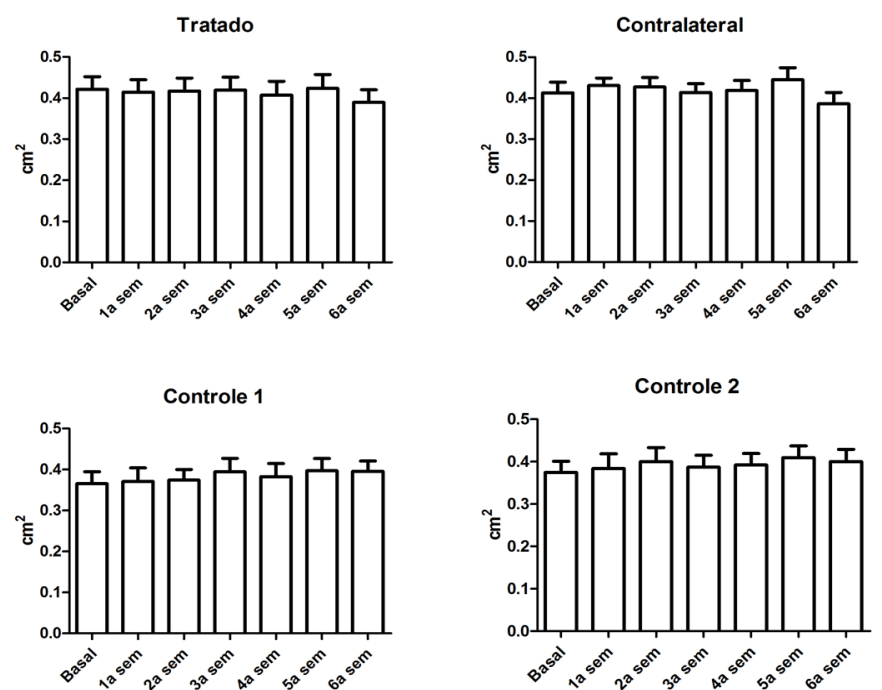

Fig.7. Médias e erros padrões das áreas externas de hiperqueratose de tetos em vacas submetidas ou não à terapia fotobiomoduladora.

\section{DISCUSSÃO}

Depois de uma consulta aos principais indexadores de ciências biológicas e veterinárias da literatura internacional, considera-se que este seja o primeiro relato do uso da fototerapia por meio de LED com vistas ao controle da hiperqueratose de teto e da mastite subclínica de bovinos.

A incidência geral de hiperqueratose nessa população foi de $95,6 \%$ dos tetos afetados, sendo que mais de um terço $(35,3 \%)$ de todos os tetos apresentavam graus 3 e 4 , ou seja, já apresentavam predisposição para ocorrência de mastites. Estes resultados são elevados, uma vez que estão acima do limite aceitável que é de incidência menor que 
Vacas - Área Interna
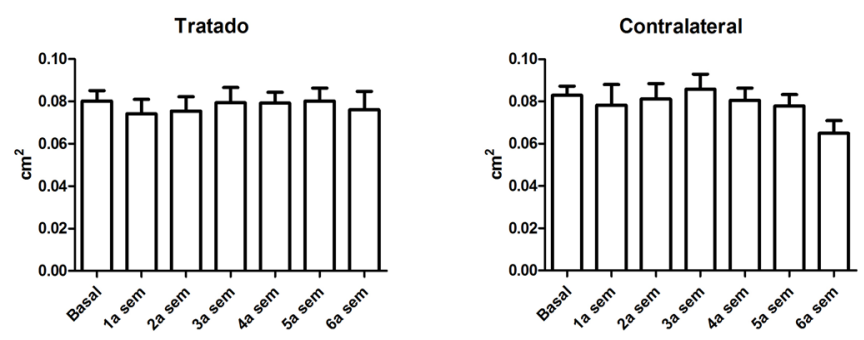

Controle 1

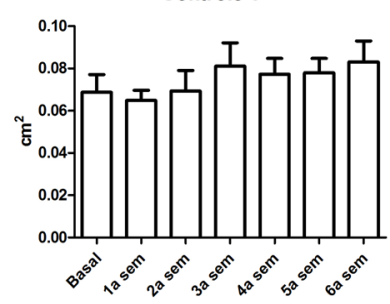

Fig.8. Médias e erros padrões das áreas internas de hiperqueratose de tetos em vacas submetidas ou não à terapia fotobiomoduladora.
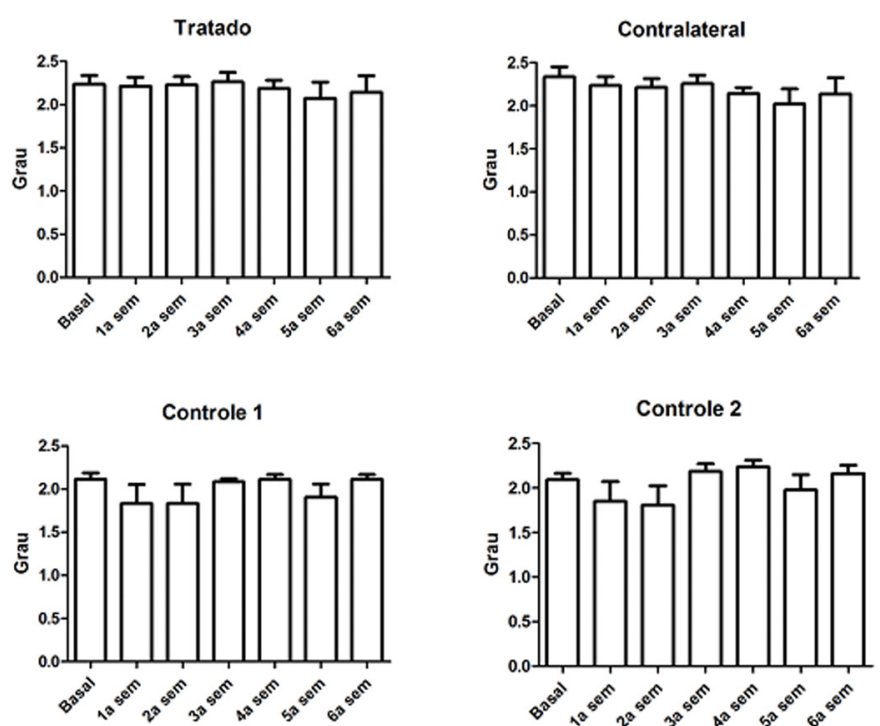

Fig.9. Médias e erros padrões dos escores para hiperqueratose de tetos em vacas submetidas ou não à terapia fotobiomoduladora.

$20 \%$ para a soma de graus 3 e 4 (Mein et al. 2001). Este resultado poderia ser inesperado, considerando-se uma fazenda que possui equipamentos com extratores automáticos com revisão regular (Quadro 1) e adota boas práticas de manejo, seguindo os 6 pontos de acordo com Natzke 1981, chegando a uma produção média de 29 litros/vaca/ dia, ou em média 9210 litros de leite anual. Contudo sabe-se que as lesões de hiperqueratose são mais graves principalmente em animais de alta produção (Blood et al. 1995, Bristol 1989).

Ao observar a distribuição dos graus de hiperqueratose entre os diferentes meses de lactação, pode-se apreciar a evolução dessa lesão durante a lactação. Nas primíparas, observa-se um aumento crescente nos valores dos escores médios, que atingem o valor máximo aos 10 meses de lactação. No caso das vacas de segunda e terceira lactação, já no início da lactação, os tetos apresentam já grau 2, havendo um aumento progressivo até os 4 a 5 meses de lactação, quando os valores se estabilizam. Esses resultados foram fundamentais para verificar a evolução da hiperqueratose nas diferentes categorias e para o delineamento dos experimentos de prevenção e terapia. No caso do experimento de prevenção, foram utilizadas apenas vacas de primeira cria, com o tratamento se iniciando até no máximo 2,5 meses de lactação, antes do grau máximo de desenvolvimento da hiperqueratose. Nesse experimento os animais foram reavaliados também no final da lactação, a fim de verificar se o protocolo instituído no início impediu a evolução da lesão. Já no experimento terapêutico, foram utilizadas apenas vacas de segunda cria, sendo o tratamento foi iniciado depois do quinto mês de lactação de, quando já havia estabilização da progressão da hiperqueratose.

No experimento com as primíparas, o diâmetro externo das lesões permaneceu constante nos tetos do grupo tratado durante, não havendo aumento significativo mesmo seis meses após o final. 0 mesmo não foi verificado no grupo controle, que apesar de se manter constante durante as primeiras semanas, apresentou aumento significativo ao final da lactação. A ausência de aumento da área externa de lesão ao final do período de lactação no grupo tratado indica efeito benéfico da fototerapia, que se manifestou não apenas no teto tratado, mas também no teto contralateral. Corroborando os efeitos aqui observados, outros pesquisadores encontraram efeitos positivos da utilização de fototerapia a base de laser auxiliando na cicatrização de feridas crônicas como úlceras de pressão em equino (Araújo et al.,2008) e úlceras de decúbito em humanos (Araújo et al. 2009). Resultados positivos foram relatados com o uso LED no tratamento de úlceras em humanos (Silva et al. 2009) e no tratamento de traumas mamilares em humanos, quando observou-se redução no tempo de cicatrização e alívio da dor no paciente (Chaves et al. 2012).

Alguns efeitos biológicos da fototerapia com LED e laser poderiam explicar o efeito preventivo no crescimento das lesões na área externa da hiperqueratose aqui verificado. Experimentos em roedores demonstraram que o uso de laser ou LED em feridas cutâneas produzidas em ratos produziu aumento significativo no número de fibroblastos (Sampaio et al. 2012). Mais além, acredita-se que o tratamento fotobiomodulador aumenta da síntese de RNA e DNA, produz incremento na produção de ATPs, aumenta a proliferação de fibroblastos e a síntese de colágeno, e estimula a angiogênese (Clark et al. 2003, Houreld 2014).

Apesar do efeito benéfico na área externa, cabe ressaltar que a fototerapia não foi suficiente para inibir a evolução do grau de lesão nos tetos tratados. Conforme observado na Figura 6, houve aumento significativo do escore para lesão ao final da lactação (seis meses após o período de tratamento) no teto tratado. Apesar dos tetos contralaterais e controles não apresentarem aumento significativo, também observaram-se valores superiores ao final do experimento. Os valores de $\mathrm{P}$ muito próximos do nível de sig- 
nificância nos tetos contralaterais e controles e a ausência de diferença significativa na comparação dos tratamentos no tempo final demonstra que os aumentos foram clinicamente semelhantes em todos os tetos, ocorrendo de forma independente do tratamento utilizado.

De acordo com Nein et al. (2003), o grau de hiperqueratose piora de acordo com a ordem de parto e com o avanço do período de lactação. No presente experimento, os fatores predisponentes não foram removidos em nenhum momento. Embora as condições dos equipamentos e o treinamento dos funcionários fossem muito bons, ainda persistiram os principais fatores como a alta média de produção e a sobreordenha que, mesmo em um sistema de extração automática das teteiras, continua ocorrendo nos tetos craniais, que normalmente produzem menos leite que os caudais. Nestas condições de ordenha, o desenvolvimento da hiperqueratose não pode ser impedido.

No experimento com as vacas com lesões prévias, não se verificou qualquer diferença estatística ou sinal clínico que evidenciasse algum efeito curativo da fototerapia sobre a morfologia e aparência externa das lesões de hiperqueratose. Conforme esperado e com base nos dados do estudo observacional não houve progressão do tamanho ou do grau de hiperqueratose nas vacas após os cinco meses de lactação. Estes achados demonstram que, apesar o protocolo de fototerapia aqui utilizado apresentar algum efeito benéfico em impedir o crescimento externo da hiperqueratose em primíparas, esse não reverteu ou alterou a aparência das lesões de hiperqueratose já instaladas.

Achados relevantes foram obtidos quanto à incidência de mastites subclínicas. Enquanto em primíparas a incidência média foi em torno de 19\% em ambos os grupos, a incidência em vacas com lesões pré-estabelecidas foi $46 \%$ e $28 \%$ nos grupos controle e tratado respectivamente. Esses valores superiores nas vacas portadoras da lesão corroboram a noção de que a hiperqueratose predispõe à ocorrência de mastite (Bristol 1989, Blood et al. 1995). Mais além, nas vacas observou-se diferença estatística $(\mathrm{P}=0,02)$ entre grupos tratado e controle, demonstrando-se que a chance do animal tratado se infectar com mastite subclínica diminui entre 1,11 a 4,15 vezes em relação ao animal não tratado.

0 efeito protetor da fototerapia sobre a incidência de mastite aqui verificado deve estar associado aos seus efeitos ativadores do metabolismo celular de ceratinócitos, fibroblastos e células inflamatórias (Young 1989, Houreld 2014) com consequente melhoria da imunidade local (Young 1989). Contudo experimentos recentes têm demonstrado que a fototerapia pode controlar a proliferação de microrganismos, mesmo bactérias altamente patogênicas, com o Staphylococcus aureus resistente à meticilina (Enwemeka et al. 2009).

\section{CONCLUSÕES}

O protocolo terapêutico com uso de irradiação com LED na extremidade do teto aqui testado não foi efetivo em prevenir o desenvolvimento ou reduzir lesões instaladas de hiperqueratose em um rebanho de vacas leiterias em regime de três ordenhas diárias e com alta prevalência da afecção.
Contudo, o uso protótipo de fotobiomodulação se mostrou útil e promissor como adjuvante na prevenção do aumento de tamanho das lesões de hiperqueratose de teto de primíparas e como forma de reduzir incidência de mastite subclínicas em vacas leiteiras já acometidas.

Agradecimentos.- À Coordenação de Aperfeiçoamento de Pessoal de Nível Superior (CAPES), ao Conselho Nacional de Desenvolvimento Científico e Tecnológico (CNPq), à Fundação de Amparo à Pesquisa em Minas Gerais (FAPEMIG) e à Pró-reitoria de Pós-Graduação da Universidade Federal de Minas Gerais pelo apoio financeiro.

\section{REFERÊNCIAS}

Araújo A.R., Chaves M.E.A., Leal B.B., de Marval C.A., Pinotti M., Alves G.E.S. \& Faleiros R.R. 2008. Efeitos potenciais do laser de baixa potência no tratamento de úlceras de pressão em um equino: um estudo de caso. Fisioterapia Brasil 9:59-63.

Araújo A.R., Chaves M.E.A., Tizon A.F.F., Silva D.B., Piantino L.L. \& Azevedo V.S. 2009. Tratamento de úlceras de decúbito com laser de baixa intensidade. Fisioterapia Brasil 10:135-138.

Blood D.C., Radostis O.M. \& Gay C.C. 1995. Veterinary Medicine. $8^{\text {th }}$ ed. Book Society, London, p.379-386.

Brasil 2010. Projeções do Agronegócio 2009/10 a 2009/20. Ministério da Agricultura Pecuária e Abastecimento-Mapa, Brasília, DF. 48p.

Bristol D.G. 1989. Teat and udder surgery in dairy cattle - Part I. Comp. Cont. Educ. Pract. Vet. 11:868-873.

Capuco A.V., Mein G.A., Nickerson S.C., Jack L.J., Wood D.L., Bright S.A., Aschenbrenner R.A., Miller R.H. \& Bitman J. 1998. Influence of pulsationless milking on teat canal keratin and mastitis. J. Dairy Sci. 77:64-67.

Chaves M.E., Araújo A.R., Santos S.F., Pinotti M. \& Oliveira L.S. 2012. LED Phototherapy improves healing of nipple trauma: a pilot study. Photomed. Laser Surg. 30:43-48.

Clark C., Bryden A. \& Dawe R. 2003. Topical 5-aminolaevolinic acid photodynamic therapy for cutaneous lesions: outcome and comparison of light sources. Photodermatol. Photoimmunol. Photomed. 19:134-141.

ColdebellaI A., MachadoII P.F., Demétrio C.G.B., Ribeiro Júnior P.J., Meyer P.M., Corassin C.H. \& Cassoli L.D. 2004. Contagem de células somáticas e produção de leite em vacas holandesas confinadas. Revta Bras. Zootec. 36:623-634

Correa F.I., Prado F.S., Miranda C.M., Souza A.P.G. \& Correa J.C.F. 2003. 0 uso do laser de HeNe $(632,8 \mathrm{~nm})$ no fechamento de feridas. Fisiot. Brasil 4:144-148.

Enwemeka C.S., Williams D., Enwemeka S.K., Hollosi S. \& Yens D. 2009. Blue 470-nm light kills methicillin-resistant Staphylococcus aureus (MRSA) in vitro. Photomed. Laser Surg. 27:221-226.

Houreld N.N. 2014. Shedding light on a new treatment for diabetic wound healing: a review on phototherapy. Scient. World J. 398412 and Collection.

IBGE 2009. Coordenação de Agropecuária Municipal, Diretoria de Pesquisas, Instituto Brasileiro de Geografia e Estatística, Brasília. <http:// www.ibge.gov.br/home/estatistica/economia/ppm/2009/tabelas_ pdf/tab23.pdf>. Acessado em 20 mar. 2011.

Kana J.S., Hutschenreiter G., Haina D. \& Waidelich W. 1981. Effect of low-power density laser radiation on healing of open skin wounds in rats. Arch. Surg. 116:293-296.

Lagan K.M., McDonough S.M., Clements B.A. \& Baxter G.D. 2000. A case report of low intensity laser therapy (LILT) in the management of venous ulceration: potential effects of wound debridement upon efficacy. J. Clin. Laser Med. Surg. 18:15-22.

Lucas C., Gemert M.J.C. \& Haan R.J. 2003. Efficacy of low-level laser therapy in the management of stage III decubitus ulcers: a prospective, observer-blinded multicentre randomized clinical trial. Laser Med. Sci. 18:72-77.

Matera J.M., Tatarunas A.C. \& Oliveira S.M. 2003. Uso do Laser de arsene- 
to de gálio (904 nm) após excisão artroplástica da cabeça do fêmur em cães. Acta Cirur. Bras. 18:102-106.

Mein G.A., Neijenhuis F., Morgan W,F., Reinemann D.J., Hillerton J.E., Baines J.R., Ohnstad I., Rasmussen M.D., Timms L., Britt J.S., Farnsworth R., Cook N. \& Hemling T. 2001. Evaluation of bovine teat condition in commercial dairy herds. 1. Non-infectious factors. Proc. AABP-NMC International Symposium on Mastitis and Milk Quality, Vancouver, BC, Canada, p.1315.

Mein G.A., Williams D. \& Reinemann D. 2003. Effects of milking on teat end hyperkeratosis. 1. Mechanical forces applied by the teatcup liner and responses of the teat. Proc. National Mastitis Council Annual Meeting, Fort Worth, USA, p.114-123.

Natzke R.P. 1981. Elements of Mastites Control. J. Dairy Sci. 64:1431-1442.

Neijenhuis F., Barkema H.W., Hogeveen H. \& Noordhuizen J.P. 2001. Relationship between teat-end callosity and occurrence of clinical mastitis. J. Dairy Sci. 84:2664-2672.

Reinemann D. (s.d.) Latest thoughts on methods for assessing teat condition. Disponível em <www.uwex.edu/uwmril/pdf/MilkMachine/TeatConditionEval/07\%20 NMC\%20TCI\%20Case\%20Study\%5B1\%5D. pdf> Acessado em 16 jan. 2013.

Oliveira Sampaio S.C., Monteiro J.S., Cangussú M.C., Pires Santos G.M.,
Santos M.A., Santos J.N. \& Pinheiro A.L. 2012. Effect of laser and LED phototherapies on the healing of cutaneous wound on healthy and iron-deficient Wistar rats and their impact on fibroblastic activity during wound healing. Lasers Med. Sci. 12:1161-1169.

Sandholm M., Honkanen-Buzalski T. \& Kaartinen L. 1995. The bovine udder and mastitis. University of Helsinki, Faculty of Veterinary Medicine, Helsinki. 205p.

Santos M.V. \& Fonseca L.F. 2007. Estratégias para controle de mastite e melhoria da qualidade do leite. Manole, Barueri. 314p.

Siqueira F.C.H.N., Reinert T.C., Correa K.P., Kotz J.C. \& Bertolini G.R.F. 2004. Uso de laser de baixa intensidade, AsAlGa, 830nm, em pacientes portadores de úlceras de pressão. Reabilitar 3:10-15.

Soares J.H., Tardivo J.P., Goldenberg S., Katz S. \& Moura L.A.R. 1989. Aspectos morfológicos e histométricos da reparação tecidual das feridas cutâneas de ratos após irradiação com o Laser de Hélio-Neônio. Acta Cirur. Bras. 4:56-60.

Takezaki S., Omi T., Sato S. \& Kawana S. 2006. Light-emitting diode phototherapy at $630-3 \mathrm{~nm}$ increases local levels of skin-homing T-cells in human subjects. J. Nippon Med. Sch. 73:75-81.

Young S., Bolton P., Dyson M., Harvey W. \& Diamantopoulos C. 1989. Macrophage responsives to light therapy. Lasers Surg. Med. 9:497-505. 